Received | Modification $\mid$ Accepted $\mid$ Published

\begin{tabular}{|c|c|c|c|}
\hline $13 / 08 / 2021$ & $15 / 08 / 2021$ & $26 / 08 / 2021$ & $10 / 09 / 2021$
\end{tabular}

Original Article

\title{
A STUDY TO ASSESS THE KNOWLEDGE AND ATTITUDE REGARDING SPACING METHODS AMONG POSTNATAL MOTHERS ADMITTED IN MATERNITY WARDS OF SELECTED HOSPITALS IN VADODARA CITY
}

\author{
MRS. VARSHA SHARMA \\ Vice-Principal Pioneer Nursing College, Vadodara,Gujarat
}

Corresponding email: varshadixit0238@gmail.com

\begin{abstract}
:
Introduction;-Unintended pregnancy is still a major concern within the United States, Birth spacing is one of the major factors in order to reduce maternal and infant mortality rate. Although In our country, different governmental and non governmental agencies are working in this field to achieve that goal, a mother needs to understand more about birth spacing methods and their availability for productive future of nation. World health organization defined "Reproductive health as a state of physical, mental, and social well-being in all matters relating to the reproductive system at all stages of life. Reproductive health implies that people are able to have a satisfying and safe sex life and that they have the capability to reproduce and the freedom to decide if, when, and how often to do so. Implicit in this are the right of men and women to be informed and to have access to safe, effective, affordable, and acceptable methods of family planning of their choice, and the right to appropriate health-care services that enable women to safely go through pregnancy and childbirth."

Objectives: To find out the correlation between knowledge and attitude regarding spacing methods among postnatal mothers.

Materials and methods: This study was conducted to assess the knowledge and attitude regarding spacing methods, Non-experimental descriptive research design was adopted to achieve the goal of the study by using instrument includes, Demographical data and knowledge questionnaires, or likert like scale followed to carried out a structured interview schedule among 60 postnatal mothers admitted in maternity wards of selected hospitals of Vadodara city, The collected data was tabulated and analyzed using descriptive and inferential statistics.

Results: The findings of the study revealed that majority $26(43.33 \%)$ of the postnatal mothers had moderate knowledge, 24(40.00\%) had inadequate knowledge and only 10(16.67\%) had adequate knowledge and the majority of $36(60 \%)$ postnatal mothers have favourable attitude ,15(25\%) mothers have unfavourable attittude and only $9(15 \%)$ of them have neutral attittude towards spacing methods and additional findings of study shows that there is weak correlation between knowledge and attitude scores of postnatal mothers regarding spacing methods, is found +0.397 .

Conclusion:The study conclude that majority of mothers have moderate knowledge and favorable attitude regarding spacing methods and there is find weak correlation between knowledge and attitude of postnatal mothers regarding spacing methods, means attitudes is slightly vary according to the level of knowledge regarding spacing methods among postnatal mothers .
\end{abstract}

Keywords: knowledge, attitude, postnatal mothers, spacing methods, maternity wards.

INTRODUCTION: World health organization defined "Reproductive health as a state of physical, mental, and social well-being in all matters relating to the reproductive system at all stages of life. Reproductive health implies that people are able to have a satisfying and safe sex life and that they have the capability to reproduce and the freedom to decide if, when, and how often to do so. Implicit in this are the right of men and women to be informed and to have access to safe, effective, affordable, and acceptable methods of family planning of their choice, and the right to appropriate health-care services that enable women to safely go through pregnancy and childbirth.'India is the second most populous country and as per growth continuous updated the projected population in 2025, 363 millions for these reason many family planning programmes is running and present approach in these programme is to provide a "cafeteria choice". 
ISSN Print: 2581-8546 ISSN Online: 2582-2934

\section{NEED OF THE STUDY: -}

Currently, India's annual population growth rate is $1.74 \%$. India is the second most populous country in the world, contributing about $20 \%$ of births worldwide.

Unintended pregnancy is still a major concern within both Developed and developing countries. Various studies recommend the importance of postpartum contraception education. Although this is started prenatally, some studies concluded this education may not be helpful during the antenatal period. Therefore, postpartum contraception can be incorporated during the postpartum period within a clinic setting. With such a wide range of contraception options available today, clinicians might not be completely familiar with the appropriate contraceptive options for women postpartum based on each female's needs: breastfeeding (and how much), as well as other factors that can affect their decision.

Unintended pregnancies have long-lasting effects on the quality of life of parents and children's. Globally it is estimated that approximately $38 \%$ unintended pregnancy of all pregnancies. The Indian Government "set a goal of achieving replacement level fertility of 2.1 children per women nationally by the year 2010 (...)" (NFHS -3, 2005). This intention is still not realized: In 2009 India's women had an average of 2.72 children per woman, contrary to Germany with 1.41 children per women (Central Intelligence Agency, $2009)^{16}$.

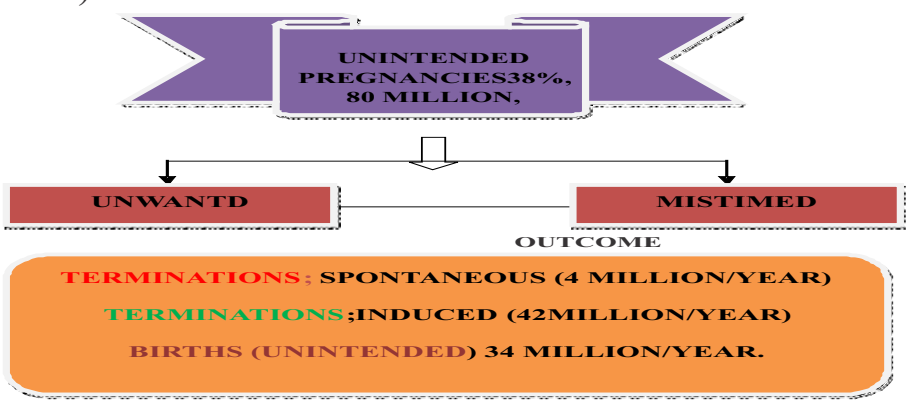

In 2000 the contraceptive prevalence rate (CPR) among married women was $\mathbf{4 8 . 3 \%}$. Contraceptive use in India is characterized by:

- The predominance of non-reversible methods, particularly female sterilization;

- Limited use of male-/couple-dependent methods;

- High discontinuation rates; and negligible use of contraceptives among both married and unmarried adolescents.
"It is estimated that if all unwanted births were prevented,

India's TFR would drop to replacement level fertility"

Less than $7 \%$ of currently married women use the officially sponsored spacing methods (pills, IUD and condoms). The reported use of traditional contraceptive methods and male/ couple dependent methods is low.

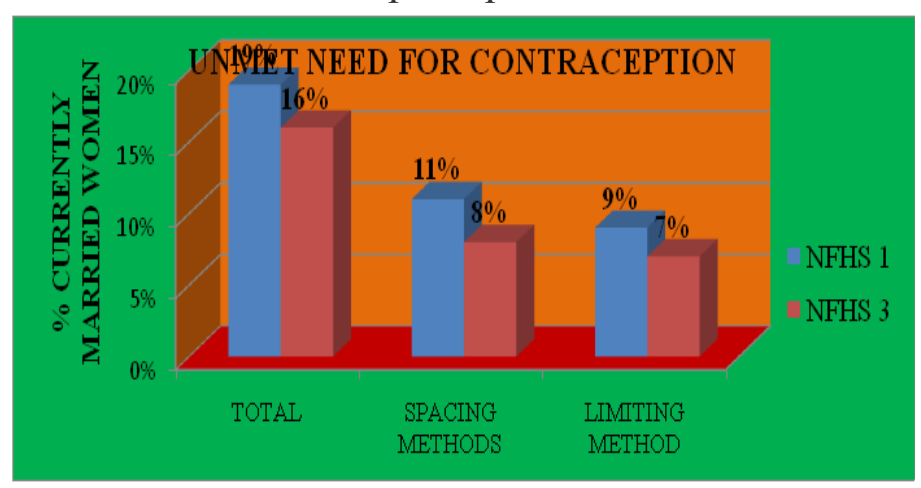

FIG-3: COMPARATIVE FIGURES OF NATIONAL FAMILY HEATH SURVEY

In order to addressing the unmet need for contraception, the government is focusing particularly in areas where fertility declines have been lagging. Issues such as adolescent reproductive health, unintended pregnancy and access to safe abortion are addressed. Counseling, access to and provision of good quality services and follow-up care are emphasized.

On situational analysis of unmet need of contraception in India, many factors like inadequate knowledge regarding methods, dependent on public sector, son preference, early marriages and limited options, high unmet need for spacing methods and low quality of services are some of the problems faced by the family planning programme..$^{20}$

The figures that will be obtained are essential for any planning of mother and child health interventions. Health team members need to know this information and the variables related to them in order to advise mothers. The figures are also essential in planning measures to reduce infant and child morbidity and mortality

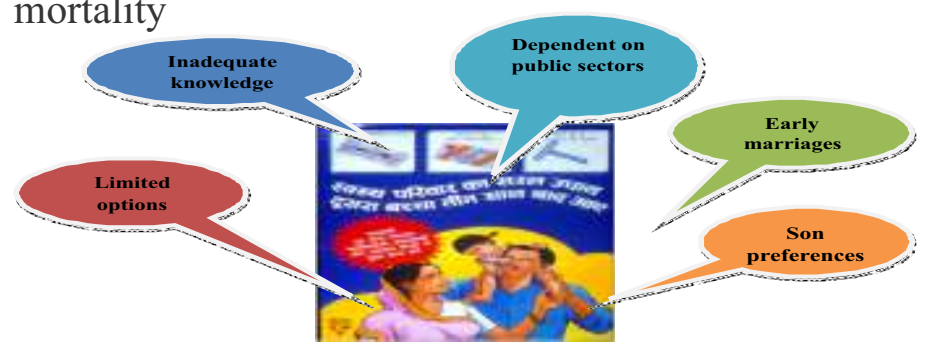


FIGURE;4 -SITUATIONAL ANALYSIS FOR UNMET NEED OF CONTRACEPTION IN INDIA

As per NFHS-III, in the state of Gujarat, $67 \%$ of currently married women use some modern method of contraception. Awareness of the three spacing methods (condom, OCP and IUD) is more than $80 \%$ in the state including Emergency Contraceptive (EC) pills, a new technology, with one out of every five women being aware of EC. $85 \%$ of women of reproductive age in the state intend to complete the family after two children. Female sterilization continues to be the major contraceptive prevalence rate (CPR). However, prevalence of spacing methods is still low with the three modern spacing methods contributing only $20 \%$ to contraceptive prevalence.

NFHS-III data shows that the median interval between successive births in Gujarat is 29 months which is less than the national average. Therefore, promotion of at least three years spacing between successive births in the state needs to be promoted vigorously to help reduce maternal and infant mortality rates. Under the state PIP for RCH-II the Government of Gujarat will strive to increase the percentage of couples using spacing methods from $18 \%$ to $30 \%$ and reduce current unmet need by $75 \%$ by 2010 . In order to cater to current unmet need in the state for spacing which stand at $4.3 \%$, promotion of spacing methods need to be strengthened. ${ }^{21}$

In Gujarat, most of the women give birth to their baby within the two years of the first delivery. Now the maternal mortality ratio is 281 per 100,000 live births and the neonatal mortality ratio is 33 per 1,000 . Thus it is absolutely necessary to find out whether they have knowledge of birth spacing. ${ }^{23}$

The NFHS- 3 marks that the female Indians use less temporary contraceptive methods like pill, Intra Uterine Device (IUD) and condom. Thus only 5\% of the currently married women use condoms, $3 \%$ takes the pill and 2\% use IUD and Female sterilization is the most widely known method: Urban and rural women use this kind of contraceptive in the same way (38\%).. Regarding the modern methods of contraceptives it is important that for example "condom use is three times as high in urban areas as in rural areas" (NFHS- 3, $2005)^{24}$
The midwives play a important role to facilitate client knowledge and choice by providing "Sound family planning information and advice" and the issue surrounding contraceptive use can promote needs that women are unable to express, midwives are in key position to use and create opportunity that may enable women to express their needs.

In India still couples are not much aware regarding spacing methods especially in rural India so the investigator has selected this topic to assess the knowledge and attitude regarding spacing methods.

\section{OBJECTIVES:}

1) To assess the knowledge regarding spacing methods amongpostnatal mothers.

2) To assess the attitude of postnatal mothers towards spacing methods.

3) To find out correlation between knowledge and attitude of postnatal mothers regarding spacing methods.

4) To find Association between knowledge and attitude scores of postnatal mothers with selected demographic variables.

\section{HYPOTHESIS:-}

1) There is a significant relationship between knowledge and attitude of postnatal mothers regarding spacing methods.

2) There is a significant association between knowledge of postnatal mothers regarding spacing methods with selected demographic variables.

3) There is a significant association between attitudes of postnatal mothers towards spacing methods with selected demographic variables.

RESERCH METHODOLOGY:This study was conducted to assess the knowledge and attitude regarding spacing methods, Non-experimental descriptive research design was adopted to achieve the goal of the study by using instrument includes, Demographical data and knowledge questionnaires, or likert like scale followed to carried out a structured interview schedule among 60 postnatal mothers admitted in maternity wards of selected hospitals of Vadodara city ,The collected data was tabulated and analyzed using descriptive and inferential statistics

RESULT:- The findings of the study revealed that 
majority $26(43.33 \%)$ of the postnatal mothers had moderate knowledge, 24(40.00\%) had inadequate knowledge and only $10(16.67 \%)$ had adequate knowledge and the majority of $36(60 \%)$ postnatal mothers have favourable attitude ,15(25\%) mothers have unfavourable attittude and only $9(15 \%)$ of them have neutral attittude towards spacing methods and additional findings of study shows that there is weak correlation between knowledge and attitude scores of postnatal mothers regarding spacing methods, is found +0.397 .

\section{Correlation between knowledge and attitude of postnatal mothers regarding spacing methods.}

\begin{tabular}{|c|c|c|c|c|c|c|c|c|}
\hline \multicolumn{2}{|c|}{$\begin{array}{c}\text { Knowledge } \\
\text { score }\end{array}$} & \multicolumn{3}{c|}{$\begin{array}{c}\text { Attitude } \\
\text { score }\end{array}$} & $\begin{array}{c}\text { ST error } \\
\text { Of } \\
\text { estimate }\end{array}$ & Slope & $\begin{array}{c}\text { Karl } \\
\text { Pearson } \\
\text { correlation } \\
\text { coefficient } \\
\text { (r) }\end{array}$ \\
\hline Mean & Stdev & Varience & Mean & Stdev & Varience & \multirow{2}{*}{7.2511} & 0.651 & $\mathbf{0 . 3 9 7}$ \\
\hline 17.13 & 4.78 & 22.86 & 34.91 & 7.83 & 61.36 & & & \\
\hline
\end{tabular}

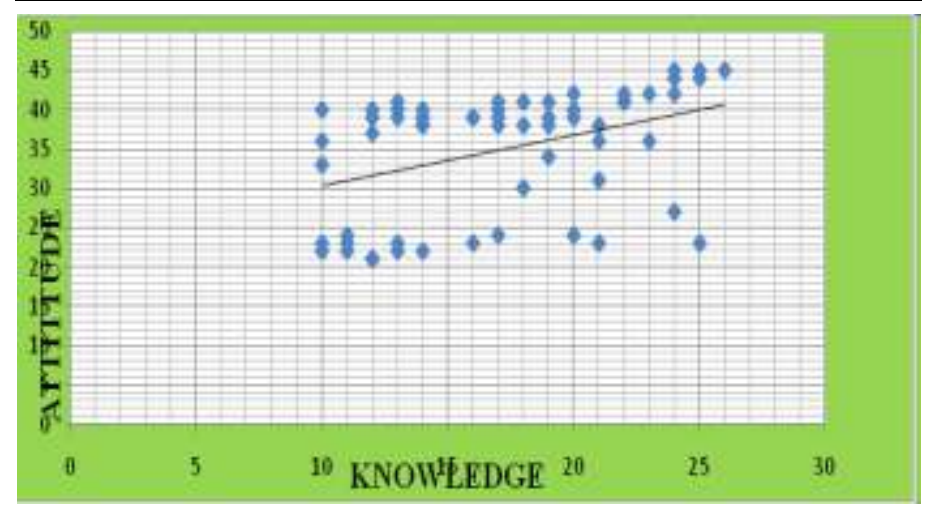

SCATTER DIAGRAMME SHOWS THE CORRELATION BETWEEN KNOELEDGE A N D AT TITTUDE OF POSTNATAL MOTHEMAJOR FINDINGS:

In this Study majority $26(43.33 \%)$ of the postnatal mothers had moderate knowledge, 24(40.00\%) had inadequateknowledge and only $10(16.67 \%)$ had adequate knowledge regarding spacing methods and the majority of $36(60 \%)$ postnatal mothers have favourable attitude ,15(25\%) mothers have unfavourable attittude and only $9(15 \%)$ of them have neutral attittude towards spacing methods.

In explorative analysis, the findings of the present study revealed that, the correlation between knowledge and attitude scores of postnatal mothers regarding spacing methods, were found +0.397 , so as per finding to analyze the weak correlation between knowledge and attitude of postnatal mothers

In present study area-wise mean percentage knowledge score of postnatal mothers regarding spacing methods, was maximum $(65.00 \%)$ mean score in the aspect of condom followed by the oral contraceptives and very less knowledge $16.50 \%$ in area of other temporary methods.

Over all area-wise mean percentage distribution of attitude scores of postnatal mothers towards spacing methods indicate that the mean percentage $77.40 \%$ of attitude score was maximum, in two areas such as birth spacing and lactation. in the area of maternal and child health mean $\%$ of attitude score was $76.20 \%, 75.80$ mean percent was scored by postnatal mothers in area of family welfare, about $75.33 \%$ mean percentage of attitude score was in area of condom,55.67\% attitude score was in area of oral pills ,53.40\% was in area of $\mathrm{Cu}$-T, and very least attitude score in area of religious aspect.The overall mean is found 34.92 , percentage $\%$ found to be $69.84 \%$, with standard deviation 8.32 measures for spacing methods.

The findings of the present study revealed that there is significance association between knowledge scores and selected demographic variables such as age $\left(\chi^{2}=\right.$ $25.19)$, educational status $\left(\chi^{2}=80.93\right)$, Occupation $\left(\chi^{2}=\right.$ $43.10)$, family income $\left(\chi^{2}=24.84\right)$, Religion $\left(\chi^{2}=19.09\right.$ ) ,age of marriage $\left(\chi^{2}=19.38\right)$, and source of information $\left(\chi^{2}=19.65\right)$, only type of family $\left(\chi^{2}=6.22\right)$ was not significant at 0.05 level. Thus it can be interpreted that there is a no significant association between knowledge and attitude of postnatal mothers with their type of family.

The findings of the study were also revealed that that the, Variables of age $\left(\chi^{2}=12.70\right)$, family income $\left(\chi^{2}=12.68\right)$, were found to be significant at 0.05 level, Thus it can be interpreted that there is a significant association between knowledge and attitude with selected demographic variables such as age and family income, educational status $\left(\chi^{2}=8.77\right)$, Occupation $\left(\chi^{2}=8.47\right)$, Religion $\left(\chi^{2}=5.69\right)$,type of family $\left(\chi^{2}=0.819\right)$, age of marriage $\left(\chi^{2}=11.35\right)$, and source of information $\left(\chi^{2}=5.12\right)$, were not found to be significant at 0.05 level, so there is no significance association between knowledge and attitude with selected demographic variables such as educational status,occupation, religion,type of family, age of marriage, and source of information.

\section{CONCLUSION}

Knowledge of the postnatal mothers was divided into three level: adequate, moderately adequate and 
inadequate knowledge and attitude is categorized into favourable. Neutral and unfavourable so as mention categories assess the knowledge and attitude regarding spacing methods among postnatal mothers and conclude that:-

Themajority of mothers have moderate knowledge and favourable attitude regarding spacing methods and there is find weak correlation between knowledge and attitude of postnatal mothers regarding spacing methods, means attitudes is slightly vary according to the level of knowledge regarding spacing methods among postnatal mothers. So there is need to promote the postnatal mothers knowledge regarding spacing methods.

\section{RECOMMENDATIONS FOR FUTURE RESEARCHERS:}

On the basis of the findings of the study, it is recommended that:-

1. A Similar study can be replicated with intervention.(Experimental and control group)

2. A Similar study can be conducted with large samples.

3. A similar study can be conducted with planned educational programme.

4. A Similar study can be conduct on couples or only male perspectives.

5. A similar study can be conduct to analyse the relationship between birth spacing methods and maternal morbidity would be useful to add, to new existing studies.

6. A Similar study can be conduct on antenatal and postnatal mothers in the terms of comparison.

7. A similar study can be conducted on adolescent girls.

8. A similar study can be conducted in community settings.

9. A comparative study can be conducted with governmental and private hospitals.

\section{REFERENCES:-}

1. Nawar L. Reproductive Health And Reproductive Rights In Arab Region, Background Paper Presented To The Arab Population Forum Beirut, November 19-21, 2004.

2. The World Bank, Atsuko Aoyama. "Reproductive Health In The Middle East And North Africa, July, 2001.
3. (World Conference Of The International Women's Year -1975

4. Miles Textbook OfMidwifery

5. Park K (2009), Textbook Of Preventive And Social Medicine $20^{\text {th }}$ Edition., M/S Banarsidasbhanot Publishers, 1167,Premnager,Jabalpur(M.P) Pp, 512-514.

6. Njogu, W. And Martin Tc. Fertility Decline In Kenya: The Role Of Timing And Spacing Births. Proceedings Of The Demographic And Health Surveys World Conference, August, 5-7, Washington D.C. Proceedings, Volume Iii: 18831901.

7. Al- Marzou Y, Farid S. Saudi Arabian Ministry Of Health Reproductive Patterns And Child Survival 1993 :53-96.Carol U. Islamic Islamic Precepts And Family Planning: The Perceptions Of Jordanian Religious Leaders And Their Constituents.

8. (Hamilton, 1997). (Robey Et Al, 1996). . Handbook Of Women's Health: An Evidence-Based Approach. Cambridge University Press. Cambridge: England.

9. Pathak, K. B., F. Griffith, Et Al. (1998). Accelerating India's Fertility Decline: The Role Of Temporary Methods. National Family Health Survey Subject Reports Mumbai; Honolulu, International Institute For Population Sciences; East-West Center.

10. Baksh L., Davis K., Davis T., Bloebaum L., Streeter N., Galloway K., Rolfs B. (1999) Unintended Pregnancy in Utah. Prams Perspectives: A Pregnancy Risk Assessment Monitoring System Quarterly Report.

11. CDC Advanced Data From Vital And Health Statistics -2004.

12. Tenth Five Year Plan (2002-2007) : "Outline efforts in different broad areas".

13. (International Confederation Of Midwives, International Confederation Of Gynecologist And Obstetricians And Ec Midwives Directives-1998)

14. Polit and Hungler (1999),'Nursing Research Principles \& Methods', Philadelphia J.B. Lippincott.

15. Birth Spacing CLUSTER REPRESENTATION and health volunteers guides, WHO(regional office of the eastern Mediterranean) 